\title{
Norma fundamental \\ del Valor
}

\section{Dante Cracogna}

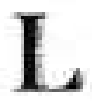

A TEORIA PURA del Derecho tiene en la teoría de la norma fundamental uno de sus pilares más importantes (1). También otras corrientes del pensamiento jurícico han desarrollado esta teoria llegando a aportaciones muy significativas: tal es el caso de la Escuela Egológica.

El pensamiento de Kelsen ha experimentado una sensible evolución en la última etapa de su producción, manifestada principalmente a partir de la segunda edición de la Teoría Pura del Derecho. La norma fundamental no escapa a esta evolución. (2) Sin embargo, en ningún momento Kelsen -ni los seguidores de la Escuela de Viena- han variado su concepción básica sobre el tema de los valores en relación con la norma funda. mental. Cabe, pues, examinar los alcances y la legitimidad cientifica de la preocupación axiológica acerca de la norma fundamental. (3)

\section{II}

La naturaleza de la norma fundamental es, para Kelsen, la de un supuesto gnoseológico que hace posible inteligir como una unidad un conjunto de normas. Sin ese supuesto no sería posible la construcción de la ciencia jurídica. Esta noción desempeña, pues, un papel constitutivo como verdadera categoría en sentido kantiano. No es una norma puesta por ningún legislador humano ni tampoco una norma de Derecho

(7) Prof, de Introducción al Derecho en la Universidad de Buenos Aires. 
Natural. (4) Sostiene Smith que "la Justicia es en el fondo, el fundamento axiológico supremo de toda legislación positiva" (5) Esta afirmación pareciera circunscribir el fundamento axiológico de las normas en la justicia a la primera constitución (constitución en sentido jurídico-positivo) (6) y a las que de ellas emanan, en cuanto son normas "puestas", con exclusión de la norma fundamental que es meramente "supuesta" (7).

Ahora bien, esta norma tan peculiar -la norma fundamental que es supuesta, o que constituye una ficción (8) - no tendría entonces connotación valorativa alguna por no ser "positum". ${ }_{i}$ Esta neutralidad axiológica estará fundada en la particular naturaleza de esta norma o simplemente -como sostiene Kelsen- en que las normas jurídicas en cuanto tales son neutras al valor? ¿Se trata del deslinde entre deber ser lógico y deber ser axiológico, o es que la norma fundamental tiene motivos especiales para no ser valiosa (positiva o negativamente)? La indagación sohre este tema no ha dado lugar a desarrollos té́ricos significativos, tal vez porque Kelsen mismo no se preocupó especialmente del asunto o porgiè la propia axiología constituye una materia que se reputa extraña a Tos preocupaciones cientificas juridicas.

Para agregar un ingrediente más al planteo de la cuestión podría formularse el interrogante sobre el carácter valioso o no de la norma fundamental referido a la norma fundamental "in concreto" $\mathrm{y}$ a la norma fundamental "in abstracto". Esta significativa distinción introducida por Vilanova (9) y sostenida también por Cossio (10) apunta a diferenciar la norma fundamental que sirve de fundamento último de la validez de cualquier sistema de normas jurídicas y aquélla en cada caso prescribe la obediencia a un preciso y determinado primer constituyente. Parecería que la disquisición acerea del valor adquiriese aquí una nueva perspectiva que interesa destacar; pero, en todo caso, se trataría de una mediatización del problema a través del desdoblamiento. Ello dejando de lado las posiciones negativas de la norma fundamental -sean totales (11) o parciales (12) - provenientes de diferentes escuelas del pensamiento jurídico.

Kelsen se ocupa de los aspectos valorativos con referencia a las normas jurídicas en varios de sus trabajos, siendo dable observar una cierta evolución en su concepción del tema -semejante a la operada en toda su obra - especialmente en la última etapa de su producción. (13) Distingue este autor dos clases de juicios de valor: los que denomina 
"juicios jurídicos de valor" y los que llama "juicios de justicia". (14) Los primeros toman en cuenta la conformidad de la conducta con las prescripciones de las normas. Estos juicios se fundan en "valores de derecho" (15) que constituyen el fundamento para calificar a las conductas a que ellos se refieren, positiva o negativamente, según se adecúen o no a la que está contenida en la norma en cuestión. Los juicios de justicia, en cambio, se fundan en "valores de justicia" y no están ya referidos a la conducta que observen los súbditos en relación con la prescripta por las normas, sino que están referidas al contenido mismo de las normas y a la actividad de los funcionarios que desempeñan funciones jurídicas en una determinada comunidad. (16)

La diferencia esencial entre una y otra clase de juicios radica en que los primeros se enuncian con relación a una norma reputada válida y son, por lo tanto, juicios objetivos donde el valor es la conformidad con la prescripción de la norma, en tanto que en los segundos no existe tal objetividad pucsto que los valores de justicia corresponden a estimaciones de carácter subjetivo. Los juicios de justicia son de naturaleza estrictamente subjetiva $y$, por consiguiente, meramente relativos, frente a los juicios jurídicos de valor que son objetivos, toda vez que no juzgan la justicia o injusticia, sino la conformidad o no de una determinada conducta con el contenido de cierta notma, (17) De alli que la Teoría Pura reiteradamente se haya pronunciado en contra de la Justicia como tema cientifico (18), pues la define como un ideal irracional. (19)

\section{IV}

Cabe investigar si la norma fundamental es susceptible de los juicios jurídicos de valor y de los juicios de justicia desarrollados por Kelsen. Sostiene este autor que "el juicio de valor según el cual lit creación de la primera constitución es un acto lícito significa que los hombres que la crearon estaban autorizados por una norma determinada para crearla" (20). Ello es así toda vez que la condición jurídica o antijurídica atribuida a una conducta por un juicio jurídico de valor supone la relación entre una conducta y una norma determinada, en este caso, la primera constitución y la norma fundamental. Por su parte la norma fundamental no tiene relación con ninguna otra norma, ya que se trata de una hipótesis del pensamiento jurídico, de una mera suposición $\left(20^{\circ}\right)$. En cambio, sí es posible un juicio de valor respecto de la primera constitución, toda vez que afirmar que ella es válida, "que su creación es un acto lícito", agnifica que es conforme con la norma básica. Agrega Kelsen: "El princi- 
pio de efectividad es la norma básica general que el pensamiento jurídico presupone cuando reconoce a un grupo de normas como la constitución de un Estado". (21) Hay, pues, en esta relación un valor de derecho cuya existencia resulta objetivamente verificable (22).

En sintesis, conforme con la Teoría Pura, la norma fundamental no es susceptible de juicios jurídicos de valor - los únicos que la ciencia del Derecho admite como objetivos- por no hallarse aquélla subordinada a otra norma jurídica. En cambio, sí es posible formular a su respecto juicios de justicia, que son de naturaleza subjetiva. Esta subjetividad -sustrato del relativismo axiológico de Kelsen (23) hace que puedan existir, en un mismo pie de igualdad, juicios diferentes y aun contradictorios acerca la norma fundamental, sin que ninguno de ellos pueda hacer valer pretensiones de verdadero.

Kelsen, en suma, no niega la preocupación por los valores en el estudio del Derecho. En palabras de Squella, "no amputa toda indagación de tipo axiológico vinculada al Derecho como objeto de estudio, sino que, cosa distinta, ciñe esta clase de investigaciones a determinados presupuestos que se encuentran en la base del pensamiento de Kelsen". (24)

El sentido del relativismo axiológico kelseniano consiste, precisamente, en que admite la formulación de juicios de justicia por parte de todos, lo cual supone que cada uno puede tener un punto de vista diferente, igualmente aceptable que los de los otros. Lo que no admite es la pretensión de validez objetiva y absoluta de alguno de los criterios individuales de justicia y la afirmación de que ese es el único verdadero. Kelsen lo dice claramente en un párrafo de Justicia y Derecho Natural, cuyo contenido es reiterado en otras obras suyas: "Una teoría positivista del derecho, y con ello quiere decirse realista, no pretende ncgar la existencia de la justicia -es preciso insistir siempre en esto-, sino únicamente afirmar que de hecho se presuponen un gran número de normas de justicia diferentes y contradictorias. No niega que la claboración de un ordenamiento jurídico positivo pueda estar determinada, y de hecho lo está generalmente, por la representación de cualquiera de esas normas de justicia. No niega que todo ordenamiento jurídico, y los actos a través de los cuales se crean estas normas, puedan ser valorados en virtud de esas numerosas normas de justicia y calificados, por tanto, de justos o injustos. Lo one sostiene esta teoría es que esos criterios de valoración no poseen 
sino un carácter relativo y que, en consecuencia, los actos creadores del ordenamiento jurídico pueden venir legitimados si se los valora con un determinado criterio y, al mismo tiempo, condenados como injustos, si el criterio de valor elegido es otro". (25)

\section{$V I$}

Según Cossio "la norma no es un juicio de valor" (26) y agrega inmediatamente que "la norma sólo presupone un juicio de valor; y esto quiere decir que no se percibe el sentído de una norma como juicio lógico sin aquél supuesto objetal". Aclara este autor que el objeto mentado por la norma - conducta humana en libertad-es valioso. De alli que no sea la norma la que tiene determinada cualidad axiológica; hay un juicio de valor que constituye su presupuesto.

Aclara Cossio en otro lugar: "Y esos valores jurídicos son inmanentes a las normas: ellos están en toda facultad y en todo deber concretos, y ellos sedimentan y justifican la fisonomía de cada Derecho positivo en su realidad. Ellos son inmanentes a las normas porque son valores de la conducta intersubjetiva y las notmas no hacen más que representar conceptualmente a la conducta en su libertad". (27)

Aplicando este razonamiento a la norma fundamental -y aceptando considerar a ésta como norma jurídica igual que las demás - resulta que no podría ser valiosa en sí misma, o por sí misma, pero tendría como presupuesto un juicio de valor. Para el caso, si la norma fundamental prescribe obedecer al constituyente originario, quiere decir que se considera valiosa la conducta de quienes prestan obediencia a este constituyente. El valor inmanente a la norma fundamental sería el de obediencia, toda vez que el juicio axiológico presupuesto en el caso rezaria: "El súbdito que obedece al constituyente originario es un buen sábdito".

Dice Cossio que la conducta "siempre es algûn orden porque siempre se determina de alguna manera" (28) y señala al orden como el valor más elemental del Derecho destacando los desarrollos de Herrfahrdt acerca del tema aunque le merezca crítica la distinción entre valores de orden y valoses juridicos. (29)

Si la norma fundamental es un supuesto gnoseológico no tiene sentido predicar el valor de dicho supuesto en cuanto tal. Ahora bien, ese supuesto tiene un contenido precisamente determinado: prescribe obede- 
cer al constituyente originario (30). Y este contenido sí es susceptible de valor, puesto que está afirmando que debe obedecerse a alguien o a las normas que alguien determine y toda norma implica un punto de vista sobre valores (en este caso sobre la conducta de los súbditos sometidos a una constitución en un determinado territorio). (31)

El contenido de la norma fundamental es el principio de efectividad -lo cual resulta muy concreto- y afirma que ha de obedecerse a quien tiene la fuerza suficiente para imponer sus mandatos. Desde este punto de vista no hay duda que legaliza la obediencia a quien tiene la capacidad de imponerse (sea por la fuerza o por acatamiento voluntario), (32) pues no otro es el sentido de la necesaria convalidación de lo fáctico que expresa la norma fundamental. (33)

La norma fundamental apunta, entonces, a realizar un valor. Resulta obvio que ese valor es el más elemental e imprescindible de todos los que campean en el ámbito jurídico: el orden. La obediencia a quién tiene capacidad de imponerse contribuye a afirmar la vigencia del orden, sin que ello significa -ni interese-que ese orden sea pacifico, solidario o justo.

El orden -manifestado como obediencia a quién manda- es una expresión y afirmación de la fuerza. El orden social es, precisamente, una organización de la fuerza y el Estado moderno es el monopolio de la fuerza frente a los particulares y los distintos grupos que actúan en su seno.

La teoria de la norma fundamental contribuye a afirmar el orden y, por lo tanto, la fuerza de quien mande en la sociedad en un determinado momento. Aquif formalismo y realismo se dan la mano: para ambos lo que verdaderamente cuenta es la fuetza que sea capaz de imponerse. La teoria se encarga luego de brindarle adecuada justificación. Pero lo que importa es el hecho de la dominación, aceptada o impuesta (principio de efectividad).

Siendo ello así no hay duda acerca de que la norma fundamental encierra un punto de vista sobre el valor: afirma el orden, por medio de la fuerza que sea capaz de imponerlo, sin importar el contenido de dicho orden (especialmente si es justo o injusto). Cualquier orden y toda fuerza, Así la ciencia juridica legitima - aún con pretensión de neutralidad axiológica- todo poder y toda dominación. 


\section{NOTAS}

(1) Cuando a fines de 1958 Kelsen fue invitado a hablar de la Teoris Pura del Derecho en la Universidad de Californis, êl mismo eligio referirse a la norma fundamental, por considerarła el tema más característico de aquélla, (Ver KELSEN, Hans Aecrea de la norma básica, traducción de Agustin Squella, Revista de Ciencias Sociales, No. 6, Valparaíso, p. 419).

(2) Cfr. el volumen Essays in Legal and Moml Philosophy, editado por Ota Weinberger (D. Reidel, Dordrecht-Molland, 1973) que contiene varios de los ensayos Jel último tiempo de Kelsen que ilustran acerea de la evolución aludída en el texto.

(3) Se ha dicho que "para una epistemologia de las ciencias juridicas, el tema de la norma fundsmenral ketseniana se torna más importante, pero en la medida que nos permite discutir la conecpeión de la ciencia normativa propuesta por su intermedio, que no obstante so aparente neutralidad y objetividad se constituye en un nuevo lngar ideológico" (WARAT, Luis Alberto, La norma fundamental ketreniana como criterio de significación, en Fstudios de Derecho, Pacultand de Derecho y Ciencias Politicas, Universidad de Antioquia, Medelín, No. 99. p. 50)

(4) KELSEN, Hans Teorla General del Derecho y del Estado, trad, de Eduardo Garcia Maynez, UNAM, México, 1979 p. 136/137; Teoria Puma del Derecho, 2a. Edición, trad, de Roberto Vemengo, UNAM, México, 1979, p. 208 y 5s.

(5) SMIrH, Jaan Carlos, El dearrollo de las concepciones jusfilosbficas, 2a, cdición, Abeledo-Perrot, Buenos Aires, 1980, p. 337. El subrayado-que destaca el calificativo "positiva" - corresponde al propio autor.

(6) KELSEN, Ilans Tearín Generul del Estado, trad, de Luis Legaz. Lacambra, Editora Nacional, México, 1965, p. 325.

(7) Tambièn podria interpretarse el aserto de este autor en el sentido de que la fundamentación axiologica de la norma fundamental - en tanto que no es nomma positiva-debe buscarse en otro valor que no sea la justicin (SMITH, op. y loc. cit.).

(8) Una ieteresante discusión sobre el tema puede verse en HARRIS, J.M., Law and Legul Science, Clarendon Press, Oxford, 1979, p. $41 / 42$ y 70 y ss.

(9) VIL.ANOVA, Jose, Vigencia y ualidez en el derecho, en El becho del Derecho, Losada, Buenos Aires, 1956, p. 147/148.

(10) Cossio, Carlos, La teorín egológica del derecho y al concepto jurílico de libertad, 2a, edición, Abeledo-Perrot, Buenos Aires, 1964, p. 436. 
(11) SAMPAY. Arturo, Introduceión a la teoria del Estado, Omeba, Buenos Aires, 1961, p. 78 y ss. $y$ 129/142. con acopio de abundantes testimonios de otros autores.

(12) Cfr. RAZ, Joseph, The concept of a Legal System, 2nd. edition, Clarendon Press Oxford, 1980, p. 140.

(13) Resulta ilustrativo comparar el pensamiento de Kelsen en Los juicios de valor en la ciencia del Derecho, trad. de Guillemo Gareía Maynez (en el volumen en la idea del Derecho Natural y otros ensayos, Losada, Buenos Aires, 1946, p. 239 y ss.) con Norma y salor, trad. de Agustín Squella N., en Revista de Ciencias Sociales, No, 6, EDEVAL, Valparaiso, 1974, p. 425 y ss.

(14) Un interesante desarrollo del tema es realizado por SQUELI.A en La tearia pura del derecho y los juicios de volor, en Estudios de Derecho, Facultad de Derecho y Ciencias Políticas, Universidad de Antioquia, Medellín, No. 99. p. 65 y s5.

(15) KELSEN, Los juicios de valar ..., P. 245.

(16) KEL.SEN, Lot juielios de valor .... , p. 262.

(17) SQUELLA, La teor ía purn del derecha..., p. 73.

(18) KELSEN, Qué es la justicia?, passim.

(19) SMITH, (op. cit., p. 343/344) critica el "habilidoso ensamble entre is función del valor y la función de la razón" que realiza Cossio, el cual "resulta en el fondo un ideal impracticable; porque muestra precisamente el mismo desajuste que exhibe toda teoría que pretende circunscribir a límites racionales el manejo empirico de una función irracional del espiritu como es el valor".

(20) KELSEN, Las juicios de valor ..., p. 257.

(20') WARAT comentando la posición de GIOJA, Ambrosio L., (La narma fundamental, en Notas de Filosofía del Derecho, No. V. Buenos Aires, p. 18 y 55 .) afirma que "detrís de las funciones de la norms fundamental gnoseológica, detectables en los textos kelsenisnos, se esconde la idea de que los valores son el resultado de actos de voluntad, que adquieren un sentido objetivo en la medida en que podemos reconocerlos como derivados de una voluntad general". Concluye este autor serialando que si se acepta $\mathbf{~ h}$ "interpretación de Gioja sobre la norma fundamental, tendríamos que admitir también, que encierra una función política encubierta" (La narma fundamental kelseniana.... p. 53).

(21) KELSEN, Los juicios de valor . , , p. 258.

(22) KELSEN, Los juicios de volor. ... p. 260. Sostiene este autor en las conclusiones del trabajo citado: "Un valor es subjetivo si su objeto es valioso sb́lo para aquéllos que se encuentran interesados en el mismo. Tal es el caso cuando la norma, 
que es el patrón del valor, estí determinada en su existencia y contenido sólo por un interés de la persona que presupone la norma. Un valor es objetivo si su objeto es valioso para todes. Tal es el caso si la norma, que es el patrón đe valor, est determinada en su existencia y contenido por hechos objetivamente verificables" (p. 264).

(23) Resulta por demás ilustrativa esta afirmación de Kelsen: "Ninguna norma perte neciente a un orden juridico positivo, y que ha sido creada en conformidad con la constitución, puede ser considerada como derecho invilido porque su contenido no esté de acuerdo con una norma que no pertenezea a ese mismo orden. La norma bisica de la Teoría Pura del Derecho es la razón de la validez de un derecho tanto democrítico como autocrítico, de an derecho capitalista como socialists, de cuslquier derecho positivo, ya sea que se lo considere justo o injusto" (Acerca de la norma batrica, p. 423).

(24) SQUELLA, Derecho, desobediencia y justicia, EDEVAL, Valparaiso, 1977. p. 377.

(25) KELSEN, Justicia y Derecho Natural, trad, de Elías Díaz, en Crítica del Derecho Natural, Taurus, Madrid, 1966, p. 101.

(26) Cossio, La Teoría Egológica..., p. 741

(27) Cossio, La Teor í Egologica ...., p. 751.

(28) COSSıO, La valonación jurídica y la ciencio del derecha, Arayó, Buenos Aíres, 1954, p. 92 .

(29) COSSı, El concepto puro de revolución, Bosch, Barcelona, 1936, p. 136.

(30) KELSEN, Teorín Pura ..., p. 217/219.

(31) Sobre este punto realiza Herrahrdt un agudo análisis que pone de relieve la conexibn intima entre Derecho y Polítiea en la base del ordenamiento jurídico. Cft. HERRFAHRDT, H., Revolución y ciencin del derecho, trad, de Antonio Polo, Revista de Derecho Privado, Madrid, 1932, p. 95 y ss.

(32) Acerea de esta cuestión puede consultarse la opinión de distintos autores en CAtTANEO, Mario A. El concepto de revolución en la Ciencia del Derecho, Depalma, Buenos Aires, 1968, p. 135.

(33) Para un desarrollo más amplio ver: CRACOGNA, Dante, Acenca del concepto de constitución en Carl Sehmitt y Hans Kelsen, en Primer Congreso Internscioaal de Filosofia del Derecho, Volumen I, La Plata, 1982, p. 93/96. 